\title{
DESBROTAMENTO DE TUBÉRCULOS-SEMENTE DE BATATINHA
}

\author{
O. J. Boock
}

Engenheiro agrônomo, Seção de Raizes e Tubérculos, Instituto Agronômico de Campinas

\section{1 - INTRODUÇÃO}

A perda dos brotos de tubérculos-semente de batatinha, (Solarum tuberosum L.) em virtude de causas diversas, como: transporte, troca de embalagem, plantio mecanizado, etc., vem sendo apontada, entre nós, como uma das principais razões do baixo rendimento, na cultura desta solanácea.

A fim de se avaliarem os efeitos sôbre a produção e ocorrência de falhas, do plantio de tubérculos desbrotados uma ou mais vêzes, iniciou-se, em 1943, uma série de experiências dessa natureza. Primeiramente, foram comparados os tubérculos desbrotados umas duas ou três vêzes com os não desbrotados. Posteriormente, êsse plano foi modificado de maneira a serem estabelecidas maiores variações nas épocas das desbrotas.

A respeito do assunto, vários trabalhos foram publicados. Wolny (2) observou que os tubérculos brotados e dos quais foram arrancados os brotos, uma, duas, ou três vêzes, produziram pouco menos do que os não desbrotados, dando, porém, maiores percentagens de tubérculos pequenos. Emilsson e Gustafsson (3) estudaram a influência do armazenamento e desbrotamento sôbre sete variedades de batatinha, chegando às seguintes conclusões: uma desbrota não influiu sôbre a futura brotação; duas desbrotas provocaram um aumento apreciável no número de falhas em duas variedades, e três desbrotas aumentaram consideràvelmente o número de falhas em tôdas as variedades, exceto em uma. Comparando tubérculos não desbrotados e desbrotados, conservados à luz, a $0^{\circ}, 5^{\circ}$ e $10^{\circ} \mathrm{C}$, êsses pesquisadores verificaram que as plantas provenientes de tubérculos brotados à luz se desenvolveram mais ràpidamente, seguidas por aquelas provenientes de tubérculos desbrotados uma vez e conservados a $10^{\circ} \mathrm{C}$. $\mathrm{O}$ armazenamento a $0^{\circ} \mathrm{C}$ retardou consideravelmente o desenvolvimento das plantas, provocando um maior número de hastes por planta. Duas desbrotas e temperatura de $10^{\circ} \mathrm{C}$ aumentaram ainda mais o número de hastes, quando comparadas com igual temperatura e uma só desbrota. O tamanho médio dos tubérculos colhidos foi, no geral, pequeno para os conservados a $0^{\circ}$ e $10^{\circ} \mathrm{C}$, com duas desbrotas, e grande, para os brotados à luz e conservados a $10^{\circ} \mathrm{C}$, com uma desbrota. Essas diferenças são explicadas pelo maior ou menor desenvolvimento das plantas e pelo número de hastes.

Observações feitas por Cadoux (4) sôbre a variedade holandesa "Bintje", e na qual procedeu a desbrotas logo após o início da brotação ou tardiamente, vieram indicar que o desbrotamento retardado provoca uma diminuição do rendimento. 
Mc Cubbin (5) constatou em seus experimentos que as batatas desbrotadas produzem maior número de hastes por planta e como consequência há uma percentagem maior de tubérculos, muito embora a produção não tenha sido maior.

\section{2 - PLANO EXPERIMENTAL}

Antecedendo os trabalhos de campo, foram instaladas três experiências de caráter preliminar, uma em vasos de barro com capacidade para $10 \mathrm{~kg}$ de terra e outras duas em canteiros. Nessas experiências, utilizaram-se as variedades "Paraná Ouro" e "Konsuragis", cujos tubérculos foram desbrotados uma, duas e três vêzes, a fím de serem comparados com os que não foram desbrotados.

Nas experiências definitivas iniciadas em 1943 e terminadas em 1951, realizadas em Campinas e Santa Rita do Passa Quatro (1), foram mantidos fixos a adubação, profundidade de plantio e espaçamento.

As parcelas experimentais foram distribuídas pelo sistema de blocos ao acaso, com quatro ou cinco repetições. Para uma das experiências (n. ${ }^{\circ}$ ), apenas foram empregados quatro tratamentos, isto é, sem desbrotas e desbrotando uma, duas e três vêzes, ao passo que, para as demais (4 em Santa Rita e 3 em Campinas), foi aumentado o número de tratamentos para oito, obedecendo à seguinte distribuição:

1 - Sem desbrotas (testemunha)

2 - Uma desbrota - 1 mês após a brotação.

3 - Idem - 2 meses após a brotação.

4 - Idem - 3 meses após a brotação.

5 - Duas desbrotas - 1 e 2 meses após a brotação.

6 - Idem - 1 e 3 meses após a brotação.

7 - Idem - 2 e 3 meses após a brotação.

8 - Três desbrotas - 1, 2 e 3 meses após a brotação.

Os tubérculos utilizados nas experiências foram postos a brotar em lugar ventilado, claro e onde a temperatura oscilou entre $17^{\circ}$ e $25^{\circ} \mathrm{C}$, durante o período que aí permaneceram.

As variedades não foram sempre as mesmas. Assim, considerando-se apenas as experiências que chegaram a bom término, isto é, seis delas, quatro em Campinas e duas em Santa Rita do Passa Quatro, utilizaram-se a "Konsuragis" (6. e 8. experiências), "Ostbote" (4." experiếncia), "Eigenheimer" (7. experiência), "Casca Roxa" (10." experiência) e "Voran" (11.. experiência).

\section{3 - RESULTADOS OBTIDOS}

Nas experiências preliminares em que foram empregados tubérculos não desbrotados e desbrotados, uma, duas ou três vêzes, foi notado que, aumentando o número de desbrotas, houve um forçamento da brotação das gemas dormentes, dando, como consequência disso, maior número de hastes por planta, o que influiu ligeiramente sôbre o aumento do número 
de tubérculos do tipo médio e miúdo. As falhas foram um pouco maiores nos canteiros e vasos onde se desbrotou três vêzes, e as produções pouco deferiram, demonstrando, porém, uma ligeira superioridade dos tratamentos sem desbrota c desbrotado uma vez, sôbre os com duas e, principalmente, três desbrotas.

Nas experiências definitivas, sôbre condições normais de campo, e onde se estabeleceu maior número de combinações na época das desbrotas, constatou-se que um maior número de desbrotas provoca um aumento do número de falhas, aumento êsse que tende a crescer à medida que os tubérculos vão perdendo a sua turgescência, devido a um desgaste maior das suas reservas, na formação de novos brotos. Assim, na experiência $\left(10 .^{a}\right)$ onde foi utilizada a variedade "Casca Roxa", houve, nas batatas sem desbrota, seis hastes em média por planta, ao passo que, com três desbrotas, êsse número aumentou para nove.

Quanto à ocorrência de falhas e desenvolvimento das plantas, ficou demonstrado que uma desbrota quase nada influiu sôbre o aumento de falhas, principalmente quando feita logo após o início da brotação, época em que os tubérculos-semente ainda estão com reserva suficiente para alimentar nova brotação. Com três desbrotas, já aumentou bem o número de falhas, conforme mostram as percentagens constantes do quadro 1 e figura 1 , principalmente as de Santa Rita do Passa Quatro.

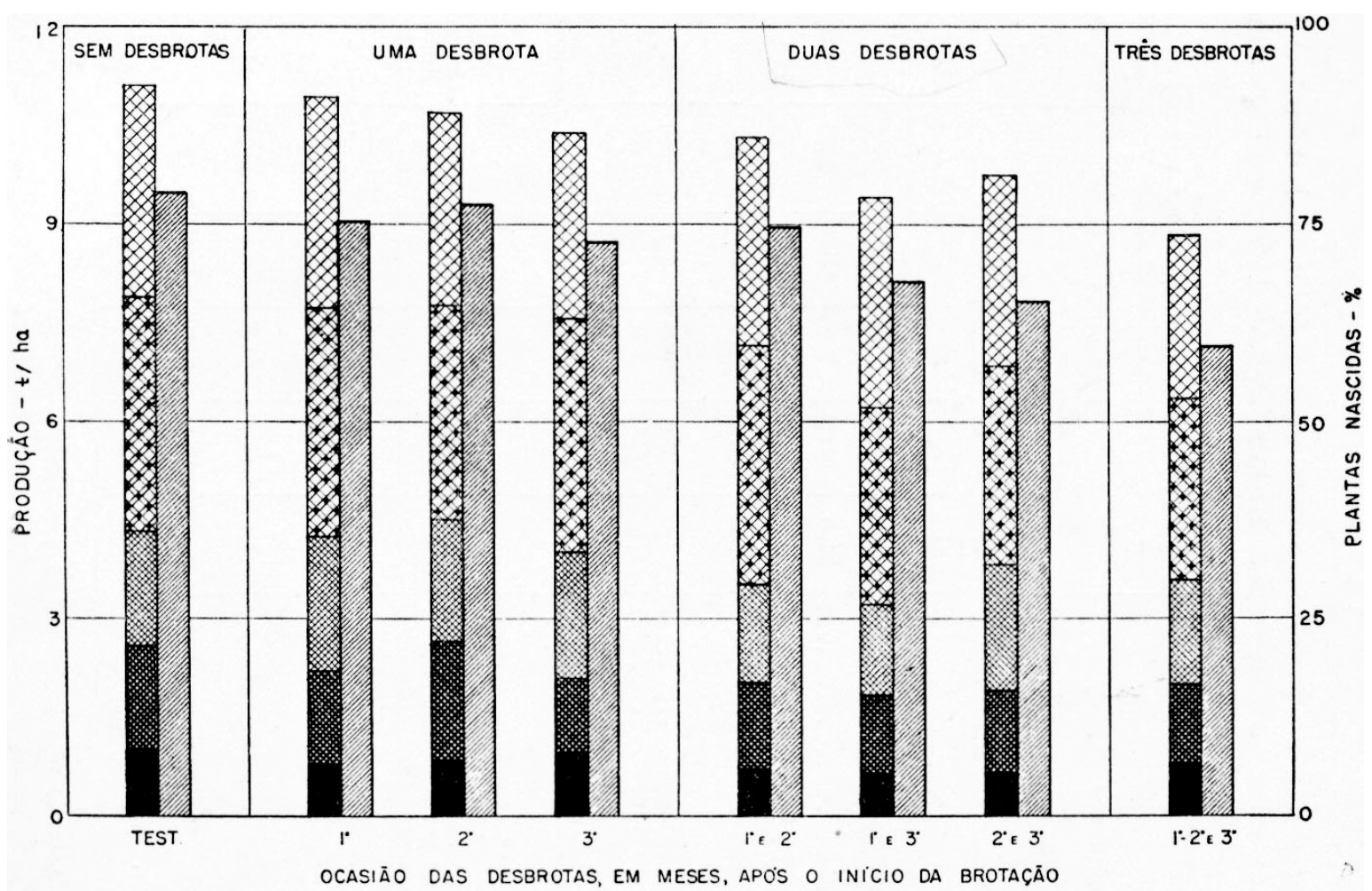

ACIMA DE 80,

DE 60a809 DE 40a609

WDDE 20 a 409

WABAIXO DE 2Og(REFUGO)

PLANTAS NASCIDAS

Figura 1. - Percentagens médias de plantas nascidas e produçũes, em toneladas por hectare, dos diferentes tipos de batatinha, em seis experiências de desbrotamento de tubérculos, instaladas nas Estações Experimentais de Campinas e Santa Rita do Passa Quatro. 


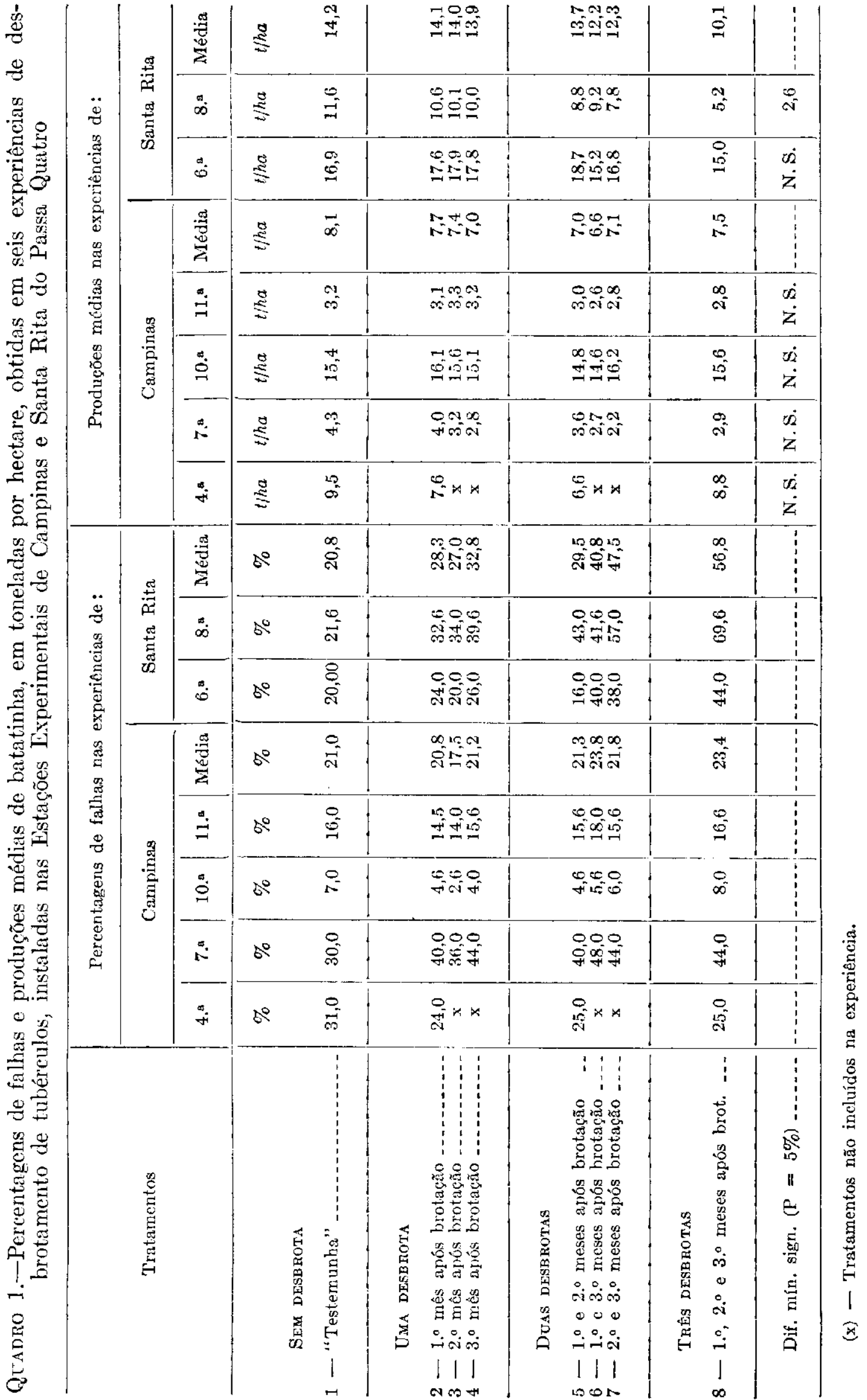


O desenvolvimento das plantas nos diferentes tratamentos pouco diferiu. Nos desbrotados, entretanto, o maior número de hastes conferiu muitas vêzes certa uniformidade e uma melhor aparência vegetativa às plantas. Em alguns casos, sobretudo com as variedades "Konsuragis" e "Voran", uma desbrota trouxe grande uniformidade à cultura, fazendo amadurecer tôdas as plantas ao mesmo tempo.

As produções pouco diferiram, a não ser em uma das experiências em Santa Rita $\left(8 .^{a}\right)$, onde, como consequência do maior número de desbrotas, houve um decréscimo na produção. Assim: o tratamento três desbrotas deu $69,6 \%$ de falhas, caindo, por conseguinte, a produção para 5,2 toneladas por hectare, enquanto no sem desbrotas, embora tenha falhado bastante $(21,6 \%)$, devido às condições adversas de clima, a produção foi de 11,6 toneladas por hectare.

A classificação dos tubérculos colhidos revelou, de um modo geral, que as diferenças entre os tipos, foram pouco afetadas pelo número de desbrotas, porém as maiores percentagens de tubérculos, acima de 80 gramas, ocorreram nos tratamentos sem desbrotar ou desbrotado uma só vez, conforme mostra o quadro 2 e figura 1 , onde se acham reunidas as percentagens médias de diferentes tipos.

\section{4 - CONCLCSÕES}

Do exposto no presente trabalho, chega-se às seguintes conclusões, de ordem geral : a) tubérculos-semente que não sofreram desbrotas, deram as maiores produções, falhando menos e produzindo maior quantidade de tubér-

Quadro 2.- Percentagens de cinco diferentes tipos de batatinha, classificados segundo o pêso médio e provenientes de cinco experiências, instaladas nas Estações Experimentais de Campinas e Santa Rita do Passa Quatro

\begin{tabular}{|c|c|c|c|c|c|}
\hline Tratamentos & $\begin{array}{l}\text { acima } \\
\text { de } 80 \mathrm{~g}\end{array}$ & $\begin{array}{c}\text { de } 60 \mathrm{a} \\
80 \mathrm{~g}\end{array}$ & $\begin{array}{c}\mathrm{de} 40 \mathrm{a} \\
60 \mathrm{~g}\end{array}$ & $\begin{array}{c}\text { de } 20 \mathrm{a} \\
40 \mathrm{~g}\end{array}$ & $\begin{array}{l}\text { abaixo } \\
\text { de } 20 \mathrm{~g} \\
\text { (refugo) }\end{array}$ \\
\hline SEM DESBRota & $\%$ & $\%$ & $\%$ & $\%$ & $\%$ \\
\hline 1 - "Testemunha" & 9,0 & 14,0 & 15,5 & 32 & 29,5 \\
\hline UMA DESBROTA & & & & & \\
\hline $\begin{array}{l}2 \text { 1.0 mês após brotação } \\
3=2.0 \text { mês após brotacão } \\
4=3.0 \text { mês após brotação }\end{array}$ & $\begin{array}{l}7,0 \\
8,0 \\
9,5\end{array}$ & $\begin{array}{l}13,0 \\
16,5 \\
11,0\end{array}$ & $\begin{array}{l}19,0 \\
17,5 \\
18,5\end{array}$ & $\begin{array}{l}32,0 \\
30,5 \\
34,0\end{array}$ & $\begin{array}{l}29,0 \\
27,5 \\
27,0\end{array}$ \\
\hline DEAS DESBROTAS & & & & & \\
\hline 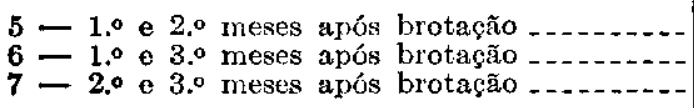 & $\begin{array}{l}7,0 \\
7,0 \\
6,5\end{array}$ & $\begin{array}{l}12,5 \\
12,5 \\
13,0\end{array}$ & $\begin{array}{l}14,5 \\
14,5 \\
20,0\end{array}$ & $\begin{array}{l}35,0 \\
32,0 \\
31,0\end{array}$ & $\begin{array}{l}31,0 \\
34,0 \\
29,5\end{array}$ \\
\hline TRẾs DESHROTAS & & & & & \\
\hline $8-1.0^{\circ}, 20^{\circ}$ e $3 .^{\circ}$ meses após brot. & 9,0 & 13,5 & 18,0 & 31,5 & 28,0 \\
\hline
\end{tabular}


culos acima de 80 gramas. Em certos casos, como, por exemplo, o que ocorre com algumas variedades (Voran), uniformizando mais a brotação impede-se que no ato da colheita ainda se encontrem plantas verdes que, ao serem colhidas, fornecem tubérculos imaturos, soltando a casca e depreciando o lote; b) uma desbrota resultou em uma ligeira diminuição da produção (não significativa estatìsticamente) do tipo de tubérculos acima de 80 gramas e na percentagem de plantas nascidas; c) o tratamento duas desbrotas mostrou-se, por sua vez, inferior ao com uma desbrota, provocando uma ligeira diminuição na produção de batatinhas e na percentagem de tipos graúdos, havendo, também, um decréscimo no número de plantas nascidas e, $d$ ) o tratamento de três desbrotas produziu menos do que cóm uma e duas desbrotas, dando grande número de falhas, muito embora as percentagens de tubérculos acima de 80 gramas pouco tenha diferido dos lotes que sofreram duas desbrotas.

Considerando-se a ocasião das desbrotas, verificou-se que as desbrotas tardias, isto é, no terceiro mês, após o início da brotação, foram as mais prejudiciais, principalmente quando se fizeram mais de uma desbrota.

\section{SUMMARY}

Three preliminary plot experiments and eight field experiments with Irish potato seed tubers were analised in order to find out the effect of desprouting prior to planting upon the whole production, percentage of failures and of large tubers (more than 80 grams).

The following conclusions can be drawn: a) seed tubers in which the sprouts were left gave higher yields, a smaller percentage of failures and greater percentage of large tubers ; b) when desprouted only once, it was noticed that yield was smaller but not significantly ; the number of large tubers was smaller and the percentage of failures was a little higher ; $c$ ) when the tubers were desprouted twice it was less favorable than a single removal of the sprouts; the tuber yield and the number of large tubers were smaller and the percentage of failures was still higher; $d$ ) when the sprouts were removed three times the yield was still lower; the percentage of failures was very high but the quantity of large sized tubers, as compared with the number when desprouted twice, did not change.

The tubers desprouted three months after the begining of sprouting, gave the poorest results particularly when it was done more than once.

\section{LITERATURA CITADA}

1. Boock, O. J. Em Relat., Seç̧ão de Raízes e Tubérculos, Inst. agron., Campinas. 1943 a 1951. (não publicados)

2. Camargo, T. de. Cultura racional da batata - Bol. Biblioteca Agrfcola Popular Brasileira. S. Paulo 5: 1-50. 1914.

3. Emilsson, B. e N. Gustafsson. Lagringsbetingelsernas iwerkan på utsădespotatisens produktiơnsformåga, Kungl Lantbruksakademiens Tidskrift. 89: 398-419. 1950.

4. Manot, G. Em Essais de dégermages. La pomme de terre française. 136: 17-18. 1951.

5. Me Cubbin, E. N. Influence of sprouts on plant emergence, growth, tuber-development and yield of potatoes. Amer. Potato J. 18: 163-174, fig. 3, 1941. 